Marquette University

e-Publications@Marquette

$7-2006$

\title{
Soft-started Induction Motor Modeling and Heating Issues for Different Starting Profiles Using a Flux Linkage ABC Frame of Reference
}

\author{
M. G. Solveson \\ Eaton Corp. \\ Behrooz Mirafzal \\ Marquette University \\ Nabeel Demerdash \\ Marquette University, nabeel.demerdash@marquette.edu
}

Follow this and additional works at: https://epublications.marquette.edu/electric_fac

Part of the Computer Engineering Commons, and the Electrical and Computer Engineering Commons

\section{Recommended Citation}

Solveson, M. G.; Mirafzal, Behrooz; and Demerdash, Nabeel, "Soft-started Induction Motor Modeling and Heating Issues for Different Starting Profiles Using a Flux Linkage ABC Frame of Reference" (2006). Electrical and Computer Engineering Faculty Research and Publications. 196.

https://epublications.marquette.edu/electric_fac/196 
Marquette University

e-Publications@Marquette

\title{
Department of Electrical and Computer Engineering Faculty Research and Publications/College of Engineering
}

This paper is NOT THE PUBLISHED VERSION.

Access the published version at the link in the citation below.

IEEE Transaction on Industry Applications, Vol. 42, No. 4 (July/August 2006): 973-982. DOI. This article is (C) Institute of Electrical and Electronic Engineers (IEEE) and permission has been granted for this version to appear in e-Publications@Marquette. Institute of Electrical and Electronic Engineers (IEEE) does not grant permission for this article to be further copied/distributed or hosted elsewhere without the express permission from Institute of Electrical and Electronic Engineering (IEEE).

\section{Soft-Started Induction Motor Modeling and Heating Issues for Different Starting Profiles Using a Flux Linkage ABC Frame of Reference}

\author{
M.G. Solveson
}

Innovation Center, Eaton Corporation, Milwaukee, WI

B. Mirafzal

Rockwell Automation/Allen Bradley, Mequon, WI

N.A.O. Demerdash

Department of Electrical and Computer Engineering, Marquette University, Milwaukee, WI

\section{Abstract:}

In order to mitigate the adverse effects of starting torque transients and high inrush currents in induction motors, a popular method is to use electronically controlled soft-starting voltages utilizing series-connected silicon-controlled rectifiers (SCRs). Investigation of semioptimum soft-starting voltage 
profiles was implemented using a flux linkage $A B C$ frame of reference model of a soft-started threephase induction motor. A state-space model of the soft-starter thyristor switching sequence for the motor and load was developed and implemented in a time-domain simulation to examine winding heating and shaft stress issues for different starting profiles. Simulation results of line starts and soft starts were compared with measured data through which validation of the model was established. In this paper, different induction machine soft-start profiles are shown, and comparisons of starting times, torque profiles, and heating losses are made. Discussion of these results and conclusions as to the near-optimum types of profiles are delineated based on peak torque, starting times, and winding heating criteria

\section{SECTION I. Introduction}

Direct online induction machine starts have many disadvantages. Torque pulsations are often large and vary from positive to negative values. These torque transients in a motor shaft are transmitted to the load, resulting in mechanical wear in the motor bearings and load couplings. Therefore, properly controlling the starting currents and torques of induction machines is of great importance in many instances. Additionally, the resulting starting currents are high, especially during the first few cycles of a starting transient. These high currents are endured by the motor and power system, causing the heating of the machine windings.

Meanwhile, certain applications such as fan loads are connected to induction motor shafts with belts. Belt-connected fan loads often require a reduced-voltage starting scheme to prevent belt slippage due to high-torque pulsations and acceleration. Accordingly, using a soft-starting technique, these problems can be greatly alleviated.

Soft starters using silicon-controlled rectifiers (SCRs), as shown in Fig. 1, are now used extensively in the industry. This starting method essentially allows the control of the voltages applied to an induction motor and hence, control of its torque and the acceleration of a machine during its starting transient. The desire to obtain near-optimum starting profiles that reduce both the mechanical and thermal stresses, through proper choice of the angles $\gamma$ and $\alpha$ in the output voltage profile (Fig. 2), was the main motivator for this paper. These starting/speed control methods are based on the premise that the root-mean-square ( $\mathrm{rms}$ ) voltage supplied to the machine can be reduced during starting and steady-state operation.

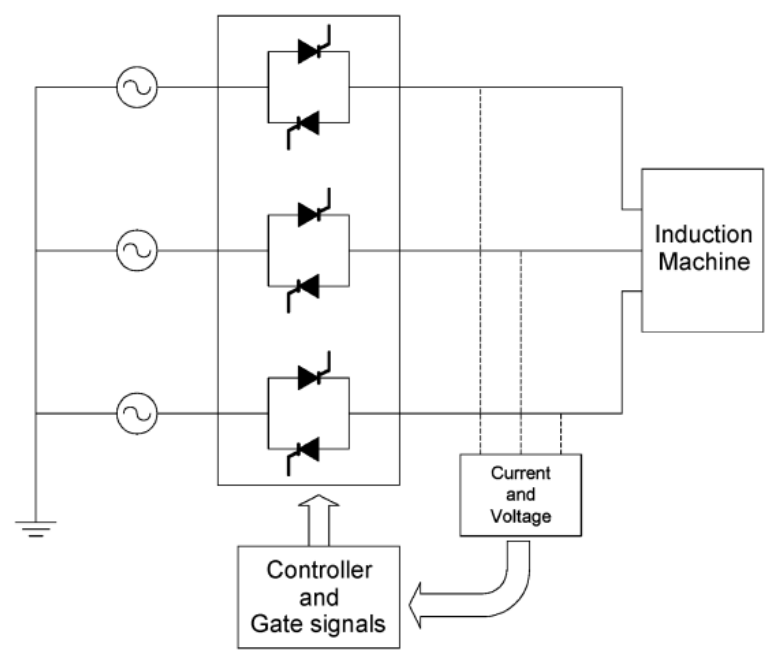


Fig. 1. Soft-starter motor system.

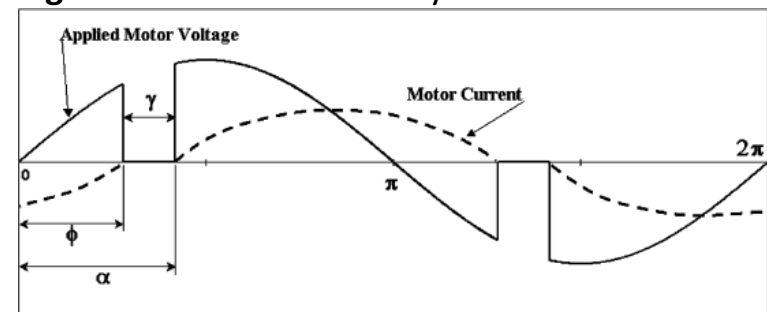

Fig. 2. Firing angle definitions.

Modeling of the steady-state performance of series-connected SCR soft-started motors is found in [1] and [2]. In these works, different modes of operation are modeled with independent sets of differential equations to account for the two-phase and three-phase operation of the machine, depending on which phases of the induction machine are allowed to conduct current. Development and use of simulation models using dq-transformation-based formulations of the induction machines can be found in [3]. This type of $d q$-frame-based simulation was enhanced to include the equations of motion and thus the simulation of an induction machine soft start from zero speed [4].

A phase-variable method where line-to-line voltages and currents were used as the control and state variables in operation modes with all three phases conducting current was developed in [5]. The other two-phase conducting modes used separate differential equations, and thus, the simulation switched back and forth between a series of state-space models, depending on the mode of operation. Methods of control were described in [6], where stability issues were addressed and comparisons of $\gamma$-control and $\alpha$-control firing angles were made (Fig. 2). Other simulations involving two-phase to three-phase operation modes, soft-start control, and other topologies are found in [7]-[8][9][10][11][12].

The simulation of a soft-started induction machine was carried out here using line-to-line stator voltages and a so-called line-to-line flux linkage state-space model [13]. This method allows one to simulate an unsymmetrical operation as well as a symmetrical operation of an induction machine using the same model formulation, which also allows the thyristors to be modeled as high or low resistances lumped in series with the induction machine winding lumped-parameter representation. This eliminates any presence of the neutral voltage term in the formulation and yields a well-conditioned set of differential equations. Since the simulation is derived in the natural $A B C$ frame of reference, the space harmonic effects associated with the magnetic circuit configurations and winding layouts of the machine can be easily incorporated into the motor inductance matrix if desired [13].

Accordingly, in this paper, an investigation of a motor soft start using a series-connected SCR topology in each phase of the stator phases (Fig. 1) was carried out through the development of a generalized flux-linkage-based state-space model for both the three-phase and two-phase conduction operations. The SCRs are fired in such a way as to notch the voltage sine wave (Fig. 2), which reduces the effective rms voltage applied to the induction machine. By applying different profiles of notch widths versus time, different motor start profiles are achieved. These various profiles, which extend in time until the motor reaches full speed, impact the peak values of currents, peak torque, and the so-called heating index integral of $\left(i^{2} d t\right)$ over the period of the starting transient, which impacts thermal considerations in a motor's windings. Often, the starting profile is set manually, and an optimal setting is not chosen. Performing simulations such as those presented here allows one to obtain near-optimum starting 
profiles for various motors and load configurations in terms of reducing peak-torque oscillations or reducing stator heating during the starting transient for the soft-starter motor topology of Fig. 1. Parametric studies that vary the profile of the notch width versus time, as well as conclusions on shaft stress, starting time, and stator heating, are presented here.

Five additional sections are presented in this paper. Section II briefly describes the model formulation and includes the well-known soft-start algorithm for motor starting. Section III compares the simulation of the starting transient of a $460-\mathrm{V}, 60-\mathrm{Hz}$, four-pole, 5-hp, squirrel-cage, three-phase induction motor to the corresponding experimental laboratory results. Section IV contains the results of a parametric study of different soft-start profiles and examines the values of currents, peak torque, and heating index aspects. Discussions of the results, future work, and conclusions are given in Section $\mathrm{V}$, and Section VI concludes the paper.

\section{SECTION II. Model Formulation and Soft-Start Algorithm}

\section{A. Balanced Motor Formulation}

The T-equivalent circuit parameters for the motor used in testing and simulation were obtained experimentally [15]. The case study motor used in this investigation was a three-phase, 460-V, 60- $\mathrm{Hz}$, four-pole, wye-connected, 5-hp, 1740-r/min, induction machine. Details on this machine and its particulars are given in Appendix A.

The relationships between the inductance parameters of the state model and the corresponding inductances (or reactances) of the conventional per-phase T-equivalent circuit of a three-phase induction motor were based on conventional well-known relationships given in [14] and are repeated in Appendix B for continuity and convenience.

This motor model formulation is based on a state-space representation of the machine windings (Fig. 3) using the natural $A B C$ flux-linkage frame of reference. Here, the terminal voltages can be related based on Faraday's law to the flux linkages and winding currents in matrix form as

$$
\underline{V}=\underline{R} \cdot \underline{I}+d \underline{\Lambda} / d t=\underline{R} \cdot \underline{I}+\underline{\Lambda}
$$

where $\underline{V}$ is $\left(\underline{V}_{\mathrm{ph}}-\underline{V}_{n}\right)$ the vector of phase to neutral voltages, $\underline{R}$ is the resistance matrix of the machine windings, $\underline{I}$ is the vector of the currents in the machine windings, $\underline{\Lambda}$ is the flux linkage vector of the machine windings, and $\underline{L}$ is the matrix of inductances of the machine windings. Additionally, the flux linkage vector can be written in terms of the inductance matrix and current vector as

$$
\underline{\Lambda}=\underline{L} \cdot \underline{I} .
$$

Upon solving for the current in (2) and substituting into (1), one obtains the key motor flux linkage state-space equation 


$$
\underline{\Lambda}=-\left(\underline{R} \cdot \underline{L}^{-1}\right) \underline{\Lambda}+\underline{V}
$$

This equation is expressed in the familiar state-space form $\underline{X}=\underline{A} \cdot \underline{X}+\underline{B} \cdot \underline{U}$, where $\underline{A}=-(\underline{R}$. $\left.\underline{L}^{-1}\right), \underline{B}$ is the identity matrix, and $\underline{U}=\underline{V}$.

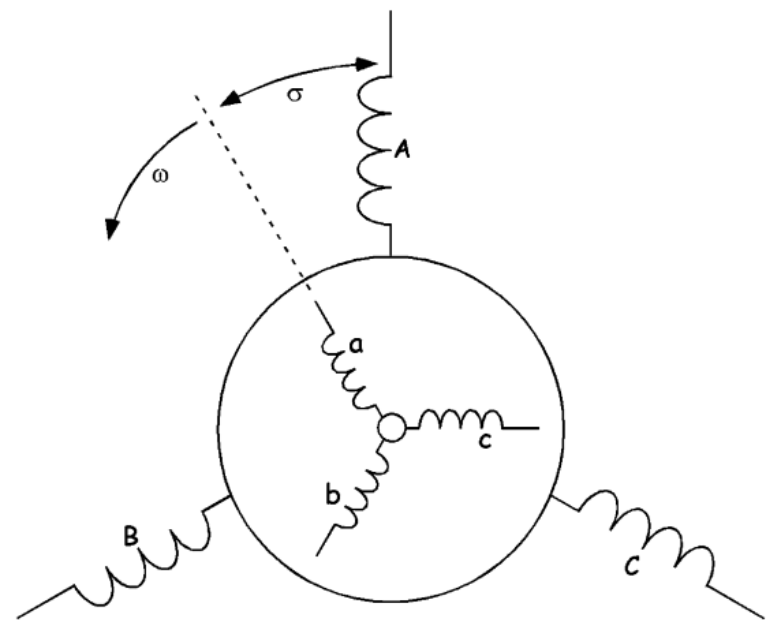

Fig. 3. Machine winding diagram.

\section{B. Unbalanced Motor Formulation}

The thyristors associated with the soft-starter circuit (Fig. 1) in this simulation were modeled as nonlinear resistors that switch between high and low states. In order to simulate this system in the $A B C$ frame of reference, where the motor impedances are not balanced when lumping these switches into the motor impedance as seen by the source, a line-to-line formulation concept was used [13]. For this unbalanced system with an ungrounded motor, the sum of the stator currents equals zero. Therefore, the stator current iC can be written in terms of iA and iB as

$$
i_{C}=-\left(i_{A}+i_{B}\right) \text {. }
$$

Substituting for iC in the flux linkage (2), subtracting $\lambda_{B}$ from $\lambda_{A}$, and $\lambda_{C}$ from $\lambda_{B}$, one obtains $\lambda_{A B}$ and $\lambda_{B C}$, which are the so-called line-to-line flux linkages that yield the line-to-line voltage formulations [13]. This method eliminates the presence of the neutral voltage $V_{n}$ from the formulation. Accordingly, one obtains an overall state-space model based on a line-to-line formulation of the following form: 


$$
\frac{d}{d t}\left[\begin{array}{c}
\lambda_{A B} \\
\lambda_{B C} \\
\lambda_{a} \\
\lambda_{b} \\
\lambda_{c}
\end{array}\right]=-\left\{\underline{R} \cdot \underline{L}^{-1}\right\} \cdot\left[\begin{array}{c}
\lambda_{A B} \\
\lambda_{B C} \\
\lambda_{a} \\
\lambda_{b} \\
\lambda_{c}
\end{array}\right]+\left[\begin{array}{c}
v_{A B} \\
v_{B C} \\
v_{a} \\
v_{b} \\
v_{c}
\end{array}\right]
$$

(5)

where $\underline{L}$ is now the $5 \times 5$ inductance matrix and $\underline{R}$ is now the $5 \times 5$ resistance matrix (Appendix $B$ ) whose circuit schematic is given in Fig. $1, v_{A B}$ is the $A$-to- $B$ line voltage, $v_{B C}$ is the $B$-to- $C$ line voltage, and $v_{a}=v_{b}=v_{c}=0$.

\section{Torque Calculation and Equations of Motion}

The developed torque of an induction motor $T_{\mathrm{dev}}$ was derived in [3] from a magnetic field energy approach and is given as

$$
T_{\mathrm{dev}}=\left(\frac{P}{2}\right) \cdot\left[\begin{array}{l}
i_{A} \\
i_{B} \\
i_{C}
\end{array}\right]^{T} \cdot \frac{d}{d \sigma}\left(\underline{L}_{\mathrm{sr}}\right) \cdot\left[\begin{array}{l}
i_{a} \\
i_{b} \\
i_{c}
\end{array}\right]
$$

(6)

where $i_{A}, i_{B}$, and $i_{C}$ are the stator currents and $i_{a}, i_{b}$, and $i_{c}$ are the equivalent three-phase rotor currents. Here, $\underline{L}_{s r}$ is the stator-to-rotor mutual inductance matrix, $P$ is the number of poles, and $\sigma$ is the rotor position angle with respect to a fixed space reference (Fig. 3).

In order to simulate the starting transient of an electric machine, the equations of motion must be included in the simulation. The motor's equation of motion was used to determine the rotor position and velocity, and is given as

$$
J\left(\frac{d \omega_{r}}{d t}\right)=T_{\mathrm{dev}}-T_{L}
$$

where $\omega_{r}$ is the angular velocity of the rotor and its rigidly connected load, $J$ is the moment of inertia in $\left(\mathrm{kg} \cdot \mathrm{m}^{2}\right)$ of the rotor and associated other rigidly connected rotating masses (Appendix A), and $T_{L}$ is the load torque including all rotational losses.

Common loads connected to induction machines include fans, traction loads, and constant torque loads. In this paper, a fan load was simulated in the parametric study. Often, fan-load torque can be expressed as a function of the square of the rotational velocity of the rotor. Thus, the load torque at zero speed equals zero (if stick friction and other external torques are neglected) and increases as a function of the square of the load speed. 


\section{Soft-Starting Topology and Operation}

The soft starter used in the experimental work is shown in Fig. 4 and is rated at 105-A continuous fullload current, three phase, $600 \mathrm{Vac}$, and $47-63 \mathrm{~Hz}$. It can support a 75-hp motor at $460 \mathrm{~V}$. This soft starter is fully controllable in terms of defining the starting voltage through defining the firing angle $\gamma$. Additionally, it has indicators for overload, jam, stall, phase loss, and phase reversal.

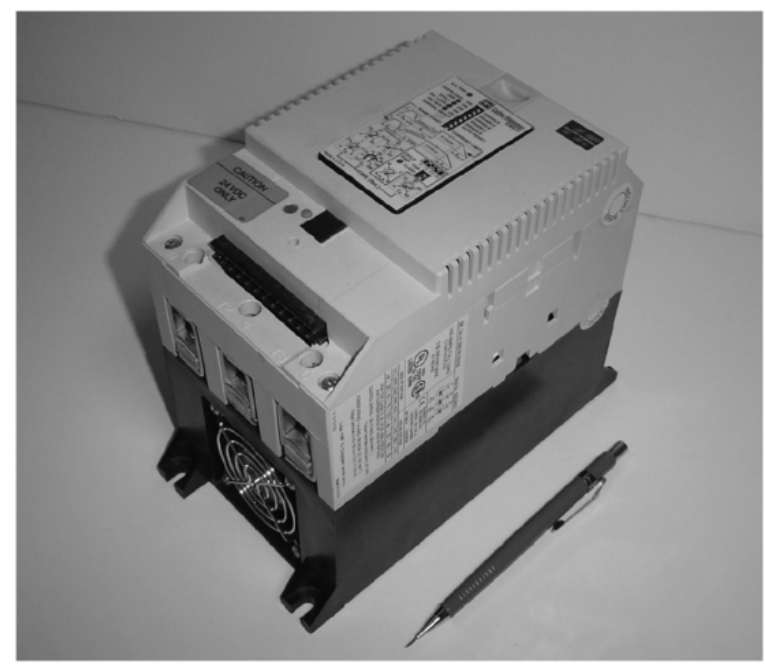

Fig. 4. Photograph of soft starter.

Notice in Fig. 1 that the soft starter consists of back-to-back (antiparallel) thyristors connected in series with each phase of the motor windings, where the motor phase currents are sensed to provide the instant of the zero-crossing of the phase current to the processor. The thyristors are selectively fired to conduct current in the appropriate phase and naturally commutate off when the current reaches zero (Fig. 2). This soft-start approach provides reduced voltage at starting that is controlled by adjusting the profile of the thyristor firing angle $\gamma$ or notch width versus time.

The method of soft starting an induction machine using this topology is well understood and found extensively in the literature. The switching sequence progresses between having two active phases conducting current, such as phases $B$ and $C$, to all three phases conducting current. Each phase switches the thyristor twice per ac cycle; thus, there are six switching events in a three-phase system per $360^{\circ}$ of an ac cycle.

To begin the switching sequence (at $t=0$ ), two phases are chosen to conduct current. In this simulation, phases $C$ and $B$ are fired first. Then, phases $B$ and $A$ are fired, and finally phases $A$ and $C$ are fired before the sequence repeats itself for the other half-cycle of each phase. The back-to-back (antiparallel) thyristor configuration allows the control of current in both directions, i.e., current flow to the load (motor) and current flow to the source; thus, both the positive half-cycle and the negative half-cycle are controlled. Once it is determined that the motor has reached full speed, the angle $\gamma$ is reduced to zero by bypassing (shorting) the thyristors.

The values for the angle $\gamma$ are defined by the user, depending on the type of soft start desired. The angle $\gamma$ may be held constant during the starting of an induction machine soft start, or it may be reduced gradually through the duration of the start until the machine has reached full speed. This can 
also be thought of as varying the notch width of the voltage waveform during the starting transient. Theoretically, an infinite number of $\gamma$-versus-time profiles is available. An induction machine soft start that has comparatively larger values of $\gamma$ for a prolonged time during the starting transient generally will have longer starting times. This is because larger values of $\gamma$ effectively reduces the rms voltages impressed upon the motor, which reduces the currents and, in turn, reduces the torque that brings the machine up to speed. Conversely, an induction machine soft start with smaller values of $\gamma$ will have shorter starting times.

\section{E. Motor and Soft-Start State-Space Model and Numerical Implementation} In this paper, the simulation was implemented using MATLAB programming language. ${ }^{1}$ The angle computation algorithm in this simulation is shown in Fig. 5. The initial conditions of the simulation include the soft-start parameters, which are defined as follows: $\phi$ is defined as $60^{\circ}$ and roughly equals the power factor angle of a motor during starting, and $\gamma$ is defined as $54^{\circ}$. This yields a smooth start with a functionally low-rms voltage applied to the motor. Complete motor and load parameters are given in [15].

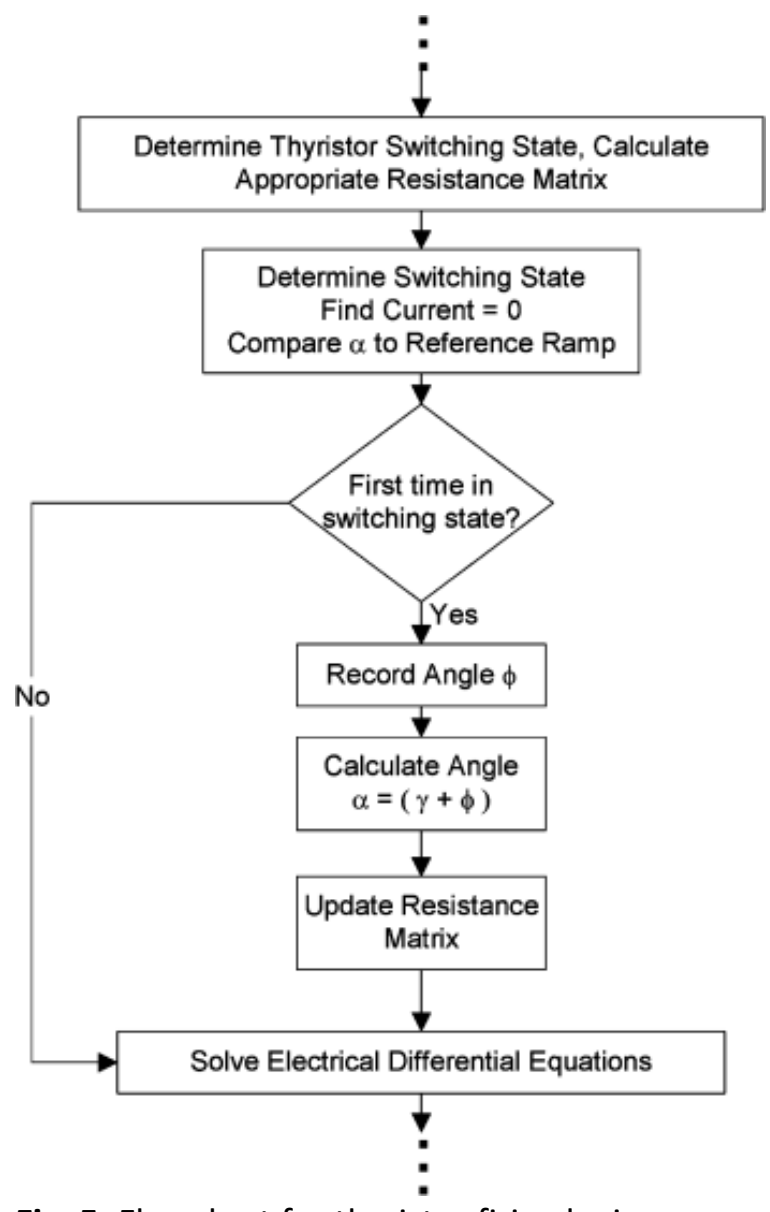

Fig. 5. Flowchart for thyristor firing logic.

The initial flux linkages and rotor speed were set to zero. Since the line-to-line flux linkage state-space formulation of (5) was used, the appropriate $5 \times 5$ inductance matrix must be formed. In the simulation code, it proved effective to first establish the original $6 \times 6$ inductance matrix and numerically convert it to the required $5 \times 5$ inductance matrix (Appendix $B$ ) using matrix algebra. 
Once the motor parameters, initial conditions, and constants are defined, the time-domain iteration loop begins using the given sinusoidal source voltages, reference ramps (used for thyristor switching), $\gamma$ profile, and switching states for the SCR switches. Once the proper thyristor switching state is defined, the $5 \times 5$ resistance matrix is recalculated. The thyristors were represented by a variable resistance where a high resistance represents an off state and a low resistance represents an on state. Here, the thyristor is represented by a variable resistor lumped in series with the machine winding phase resistance, where the values for $r_{\mathrm{thy} A}, r_{\mathrm{thy} B}$, and $r_{\mathrm{thy} C}$ are defined in Table I.

TABLE I Equivalent Thyristor Resistance Switching

\begin{tabular}{|l|l|l|l|}
\hline Phases Conducting & $\boldsymbol{r}_{\text {thyA }}($ Ohms) & $\boldsymbol{r}_{\text {thyB }}$ (Ohms) & $\boldsymbol{r}_{\text {thyc }}$ (Ohms) \\
\hline C, B & 5,000 & 0 & 0 \\
\hline B, A & 0 & 0 & 5,000 \\
\hline A, C & 0 & 5,000 & 0 \\
\hline A, B, C & 0 & 0 & 0 \\
\hline
\end{tabular}

The high-resistance value was chosen such that the simulated current during the OFF state of the thyristor correlated to the measured current during the OFF state of the thyristor. Thus, the $5 \times 5$ resistance matrix (Appendix $B$ ) was then used by substituting the correct lumped-resistance values. For further details, [15] should be consulted.

\section{SECTION III. Model Validation}

\section{A. Line Start Comparison}

Validation of the motor model was achieved first by comparing measurements to a simulation of a noload direct online start using the previously referenced $460-\mathrm{V}, 60-\mathrm{Hz}$, four-pole, 5-hp, squirrel-cage, three-phase induction motor. Much information can be obtained from the measured starting transient stator current waveform, including the inrush currents and the up-to-speed time, shown in Fig. 6 . The simulated starting transient current, which is also given in Fig. 6, correlates reasonably well with the measured results. A comparison between the peak currents and starting times is given in Table II. The comparison of the transient current peak is taken from the peak current after the first cycle because this inrush current is often due to switching transients and is dependent on the location of where the motor has been turned on in the ac cycle, thus resulting in a dc offset that cannot be exactly replicated (repeated) in the simulation. Furthermore, the discrepancy between the simulated and test peak currents is enhanced by the fact that the lumped-parameter circuit state model cannot replicate the exact electromagnetic transient taking place in the motor's magnetic circuit and windings. Greater fidelity would require a time-stepping finite-element simulation model [16], which is beyond the scope of this paper. The steady-state measured and simulated currents agree very well, and the starting times are in reasonable agreement considering the limitations of the T-equivalent circuit motor parameters obtained from blocked rotor and no-load tests [15]. 

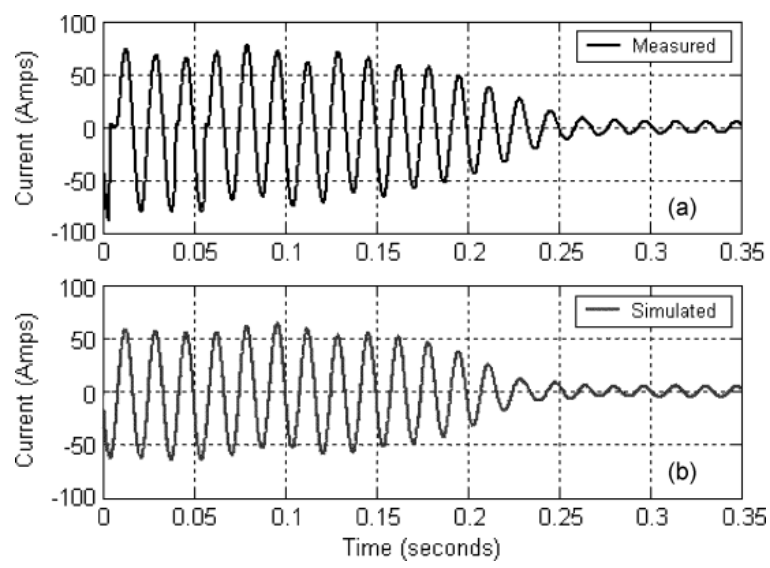

Fig. 6. No-load direct online current. (a) Measured. (b) Simulated.

TABLE II Comparison of Direct-on-Line Measured and Simulated No-Load Line Start

\begin{tabular}{|l|l|l|}
\hline & Measured & Simulated \\
\hline Peak Transient Current & 74.9 & 58.35 \\
\hline Steady State RMS Current & 3.78 & 3.51 \\
\hline Starting Time & 0.28 & 0.30 \\
\hline
\end{tabular}

Additionally, the rotor resistance has a large effect on the performance characteristics of the induction machine, including the torque. During starting transients, the rotor frequency changes from an initial value, which is equal to the supply frequency for a slip equal one per unit at start, to a value that varies with slip (the slip frequency). Then, as the motor accelerates toward full speed, the final slip is usually less than 0.1 per unit. The rotor resistance decreases from an initial ac resistance $R_{\mathrm{ac}}$, due to skin effect in the rotor bars, to a value nearly equal to the dc resistance $R_{\mathrm{dc}}$ at full speed. Such effects were beyond the scope of this paper.

Heating in the stator can be characterized by the heating index of losses in the stator windings. Integrating the square of the stator currents yields the following equation for the so-called heating index:

$$
\text { Stator Heating Index }=\int_{0}^{t}\left(i_{A B C}^{T} \cdot i_{A B C}\right) d t
$$

where $i_{A B C}$ and $i_{A B C}^{T}$ are the stator currents' vector and its transpose, respectively. This heating index versus time will be used later in the parametric simulation studies.

\section{B. Soft-Start Comparison}

Now, we compare the measurements to simulations of a no-load soft start using the same induction machine. The measured and simulated motor currents during starting are shown in Fig. 7. As can be seen clearly, there is an excellent agreement in both magnitude and shape of the starting currents, 
where the measured peak value $(21.01 \mathrm{~A})$ and the simulated value $(19.28 \mathrm{~A})$ give a starting transient current magnitude accuracy better than $8.3 \%$. The steady-state currents also show excellent agreement between the measured (5.16 A) and simulated (4.84 A) results after the machine has reached full speed (Fig. 8). The full starting transient is shown in Fig. 9. Similar differences in the starting time and peak current that occurred in the simulation and testing of the direct line start (Fig. 6) took place here in the simulation and testing of the soft start, as observed in Fig. 9. This can be attributed to the fact that the lumped-parameter circuit state model does not fully represent the physical electromagnetic intricacies of the actual electric machine. A Fourier transform spectral analysis was performed on the measured and simulated starting current waveforms to provide added validation to the simulation. The current spectrum (Fig. 9) shows good agreement for the 1st, 5th, 7th, 11th, and 13th harmonics. Although the spectrum (Fig. 10) illustrates the added harmonics that are imposed on the system, it is a relatively short transient event and is not a major concern for most applications.
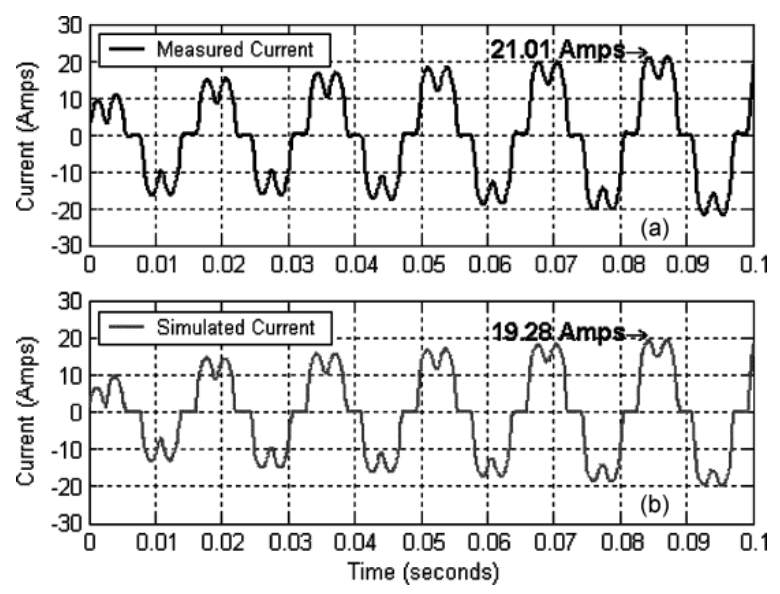

Fig. 7. Soft-start currents. (a) Measured. (b) Simulated.
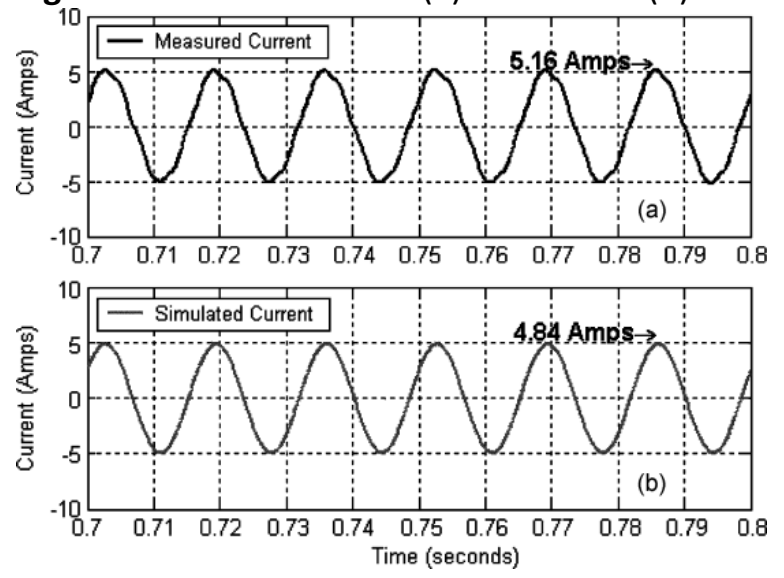

Fig. 8. Steady-state soft-start currents. (a) Measured. (b) Simulated. 

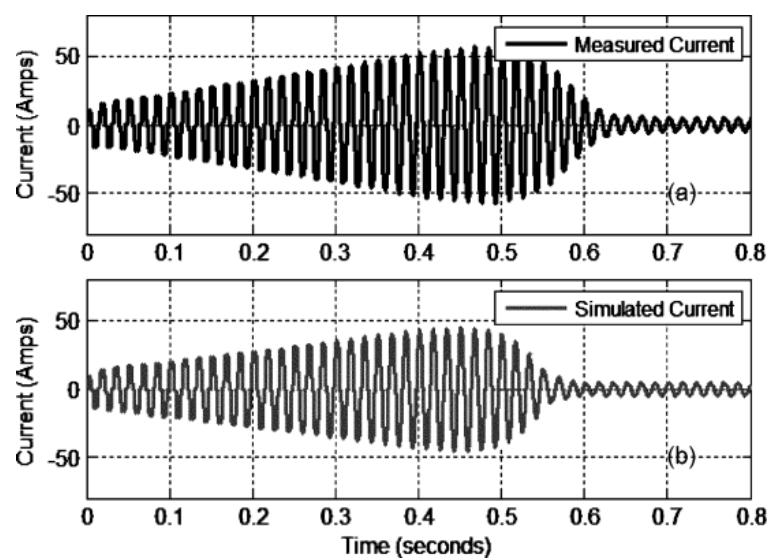

Fig. 9. Soft-start currents. (a) Measured. (b) Simulated.

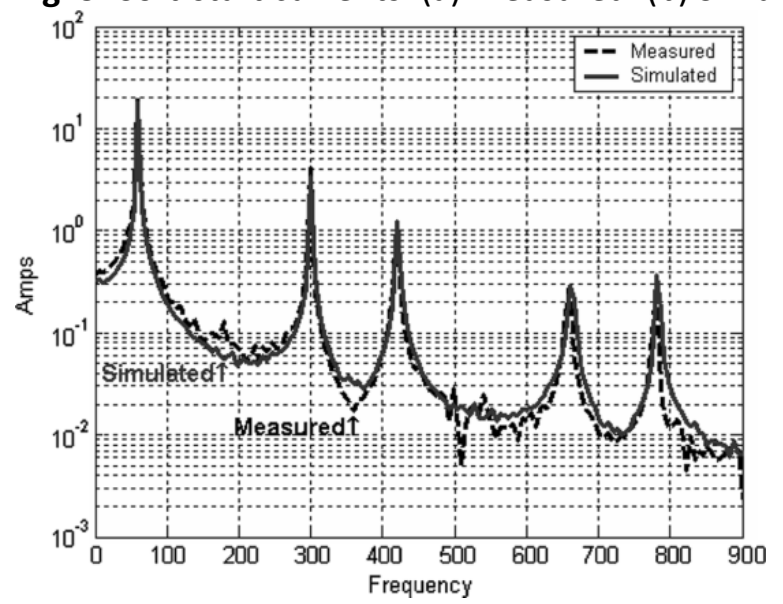

Fig. 10. Spectral analysis of measured and simulated soft-start currents.

An additional interesting phenomenon is the variation of the power factor value during the softstarting transient. This has been obtained from the simulation and is shown in Fig. 11. The calculation is performed at each zero crossing of the current by calculating the angle between the voltage and current in all three phases.

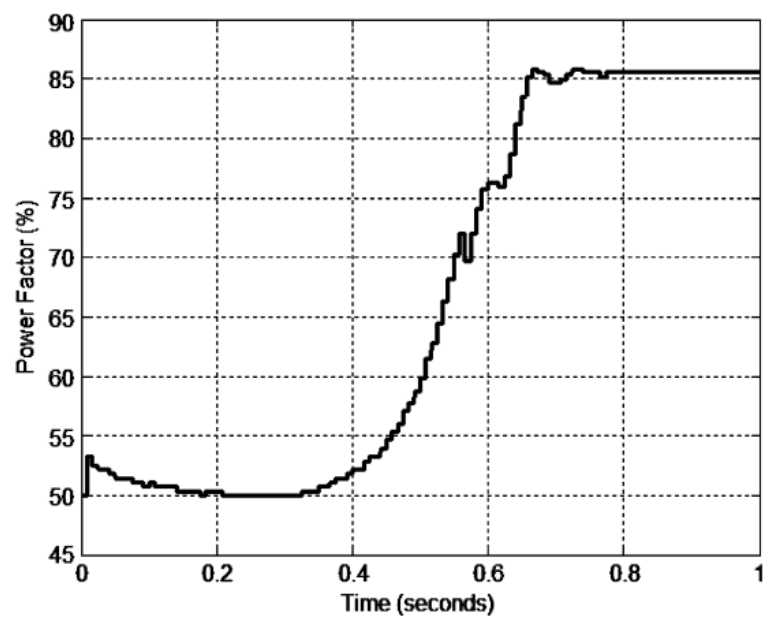

Fig. 11. Simulated soft-start power factor with fan load. 


\section{SECTION IV. Parametric Studies}

Adjusting the rms voltage versus time during the duration of the starting transient has an effect on the peak torque and motor heating. The user-defined angle $\gamma$ was assigned different profiles versus time in a parametric study to determine the effect on torque, starting time, and stator heating. For the tested and simulated case study motor with a fan load, the set of notch angle $\gamma$ time-domain profiles used in these parametric simulations are shown in Fig. 12. The angle $\gamma$ immediately begins to ramp down until the desired value of rms voltage is applied to the motor, at which point the angle $\gamma$ is held constant until the motor reaches full speed. Five final values for $\gamma$ were selected, ranging from $30.67^{\circ}$ to $4^{\circ}$.

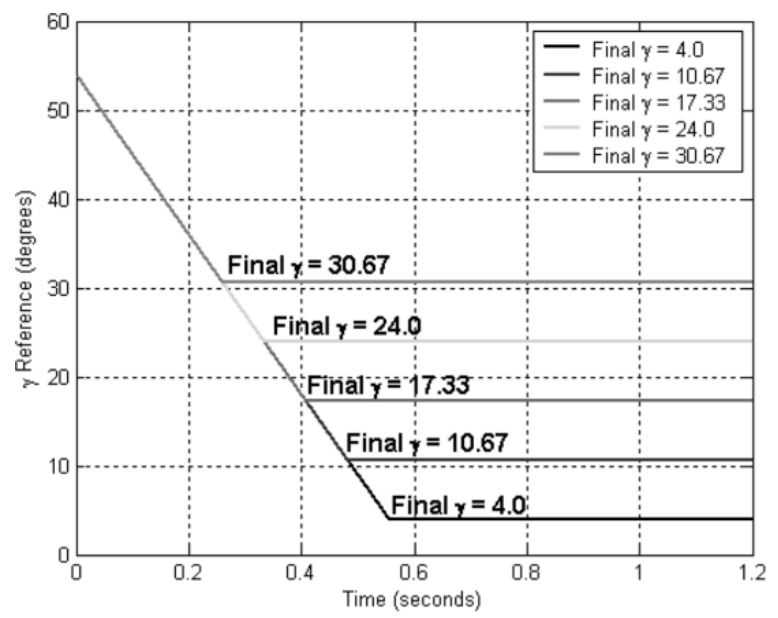

Fig. 12. Simulated gamma reference starting profile.

The resulting transient torque profiles are shown in Fig. 13. Notice the one-to-one correspondence of the ramping of the angle $\gamma$ in Fig. 12 and the corresponding torque transients shown in Fig. 13. As expected, the starting scheme with less rms voltage applied to the induction machine has less peak torque and also less average torque throughout the starting transient. Since the torque is decreased with larger values of $\gamma$, it is expected that the starting times would be longer. The resulting fan-loaded induction machine speed profiles are shown in Fig. 14.

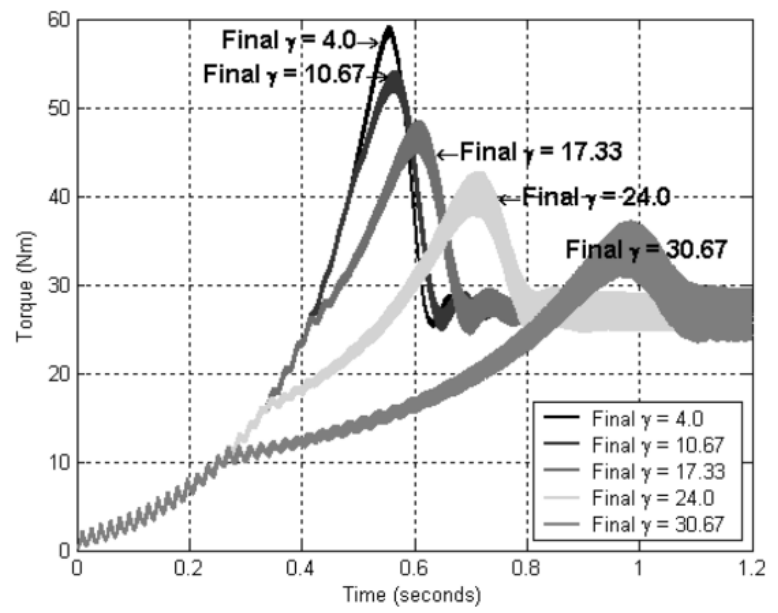

Fig. 13. Simulated developed torque versus starting profile. 


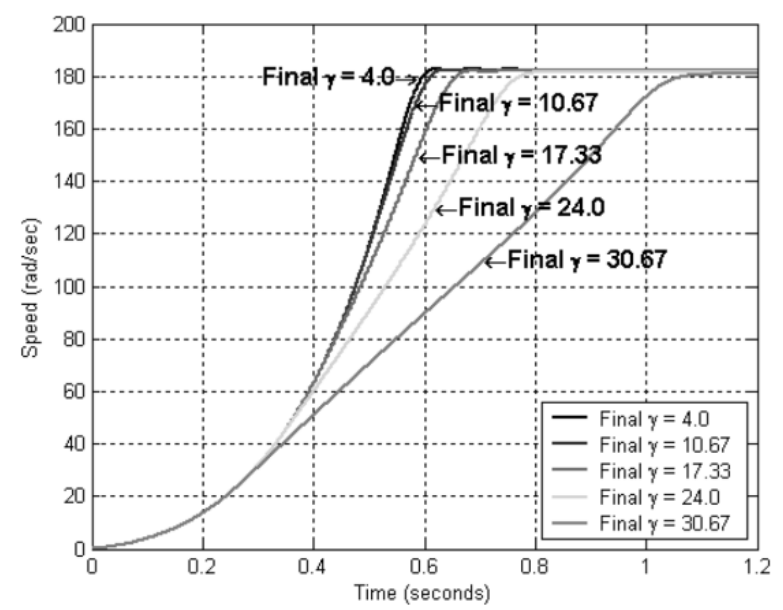

Fig. 14. Simulated motor speed versus starting profile.

The heating index for the stator windings can be found from calculations of the heating index term using the stator currents, according to (8). The calculated heating index profiles are shown in Fig. 15. Assuming that no significant heat is removed from the stator during the relatively quite short starting time, this heating index calculation helps in comparing the heat (temperature) that is generated in the motor stator windings for different starting profiles.

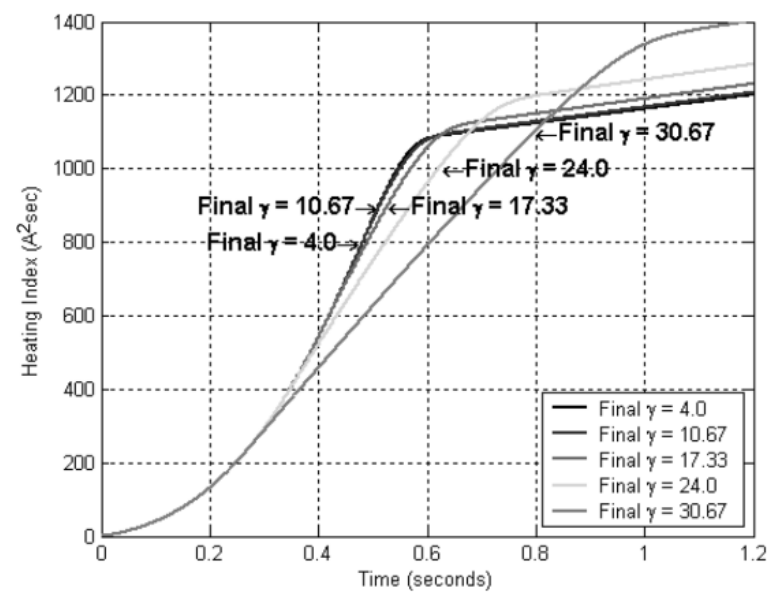

Fig. 15. Simulated heating index versus starting profile.

The data for the load stress index, which is defined here as the peak starting torque divided by the steady-state load torque, starting time, and stator heating index, is given in Table III. The lowest final value $\gamma\left(4.0^{\circ}\right)$ in the parametric simulation achieves the lowest value of the heating index; however, this value of $\gamma$ achieves the highest peak torque magnitude. The highest final value $\gamma\left(30.67^{\circ}\right)$ achieves the highest value of the heating index but also achieves the lowest load stress index. Graphically, these data are shown in Fig. 16.

TABLE III Comparison of Results for Parametric Study

\begin{tabular}{|l|l|l|l|}
\hline Final $\boldsymbol{\gamma}$ & Starting time (seconds) & Load Stress Index & Heating Index $\boldsymbol{I}^{\mathbf{2}} \mathbf{t}\left(\boldsymbol{A}^{\mathbf{2}}\right.$ seconds) \\
\hline 4.0 & 0.62 & 2.18 & 1088 \\
\hline 10.67 & 0.64 & 1.99 & 1096 \\
\hline
\end{tabular}




\begin{tabular}{|l|l|l|l|}
\hline 17.33 & 0.69 & 1.78 & 1126 \\
\hline 24.0 & 0.80 & 1.58 & 1198 \\
\hline 30.67 & 1.1 & 1.37 & 1379 \\
\hline
\end{tabular}
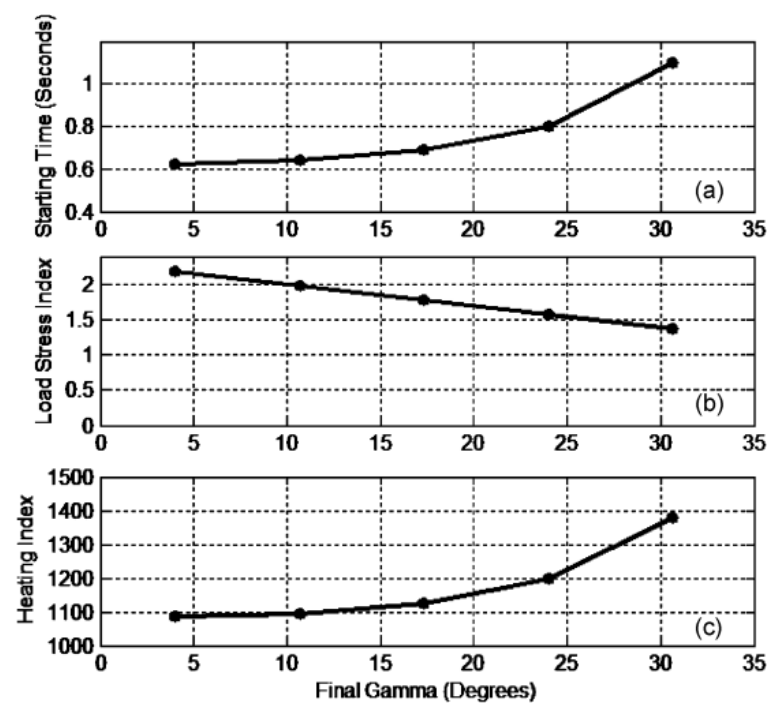

Fig. 16. Comparison of results from parametric study. (a) Starting time. (b) Load stress index. (c) Heating index.

This analysis allows one to select a starting profile based on the requirements of the desired induction machine-load application. If the motor and load cannot withstand large torques during starting, e.g., with a belt-connected load in which slippage can occur when the motor torque exceeds a certain value, then larger values for $\gamma$ will result in lower values of peak torque during the starting transient. The operator should be aware that the consequence of this leads to a longer starting time and an increase of the stator heating index. Conversely, if an operator wants to reduce the heating of the stator windings, then smaller values of $\gamma$ should be used, where the starting time will be shorter with consequent elevation in the load stress index.

\section{SECTION V. Discussion of Results and Future Work}

The model developed here can be an instrumental tool in further parametric and optimization studies to shape the starting transient of any given motor-load system to suit the operating requirements desired by practical industrial specifications and constraints.

Offline optimization can be obtained through optimization routines coupled with simulations. Improved control algorithms using online (real-time) optimization may also be applicable. This paper can further be extended into motor diagnostics during the starting transient; hence, thermal studies of the motor winding and soft-starter electronic packaging would aide in producing efficient starter systems. 


\section{SECTION VI. Conclusion}

A direct-on-line induction machine start with no load was modeled. The machine parameters were obtained experimentally, and simulations of the induction machine were validated with experimentally obtained measurements. Additionally, the generalized model of an electronically controlled soft-start transient of an induction machine was validated with experimentally obtained measurements. A parametric study of varying time-domain $\gamma$ profiles of the electronically controlled soft start was conducted. This paper yielded results that indicate that lower values of $\gamma$ result in higher values of load stress index and vise versa; lower values of $\gamma$ result in faster starting times and vise versa; and lower values of $\gamma$ result in a reduction of the stator heating index and vise versa.

In order to choose a proper profile for $\gamma$, an engineer must take into consideration these tradeoffs. For instance, if one was trying to reduce belt slippage, a higher final $\gamma$, such as $25^{\circ}$ in this study, would help to reduce the possibility of such slippage. However, it is now understood that this selection of $\gamma$ would come at the expense of increasing the heating index and increasing the starting time. Accordingly, this modeling approach can be used as a tool to arrive at near-optimum choices of the values and timedomain profiles for the soft-start angle $\gamma$ to meet any motor-load starting requirements.

\section{ACKNOWLEDGMENT}

The authors would like to thank the Eaton Electrical Group, the engineers from Cutler-Hammer for providing the soft starter for measurements, and T. L. King for his support in the application of the softstart operation and topology.

\section{APPENDIX A}

\section{Motor Data}

$$
\begin{aligned}
& R_{1}=1.88 \Omega R_{2}=1.10 \Omega \\
& L_{1}=7.45 \mathrm{mH} L_{2}=7.45 \mathrm{mH} L_{m}=0.198 \mathrm{H} \\
& \text { phases }=3 \\
& \text { poles }=4 \\
& \text { connection }=\text { wye } \\
& \text { power factor }=85 \% \\
& \text { rotor inertia }=0.0112 \mathrm{~kg} \cdot \mathrm{m}^{2} \\
& \text { total rotational inertia }=0.043 \mathrm{~kg} \cdot \mathrm{m}^{2} \\
& \text { rated voltage }=460 \mathrm{~V} \\
& \text { rated horsepower }=5 \\
& \text { rated speed }=1740 \mathrm{r} / \mathrm{min} \\
& \text { efficiency }=87.5 \% .
\end{aligned}
$$

\section{Resistance and Inductance Matrices}

The stator self-inductance $L_{\mathrm{ss}}$ is given by

$$
L_{\mathrm{sS}}=L_{1}+2 / 3 \cdot L_{m}=L_{A A}=L_{B B}=L_{C C} .
$$


The stator mutual inductance $L_{\mathrm{sm}}$ is given by

$$
L_{\mathrm{sm}}=2 / 3 \cdot L_{m} \cdot \cos \left(120^{\circ}\right)=L_{A B}=L_{B C}=L_{C A} .
$$

The rotor self-inductance $L_{\mathrm{rr}}$ is given by

$$
L_{\mathrm{rr}}=L_{2}+2 / 3 \cdot\left(N_{2} / N_{1}\right)^{2} \cdot L_{m}=L_{a a}=L_{b b}=L_{c c} .
$$

The rotor mutual inductance $L_{\mathrm{rm}}$ is given by

$$
L_{\mathrm{rm}}=2 / 3 \cdot\left(N_{2} / N_{1}\right)^{2} \cdot L_{m} \cdot \cos \left(120^{\circ}\right)=L_{a b}=L_{b c}=L_{c a} .
$$

The amplitude of the stator to rotor mutual inductance $L_{\mathrm{srm}}$ is given by

$$
L_{\mathrm{srm}}=2 / 3 \cdot\left(N_{2} / N_{1}\right) \cdot L_{m}
$$

Here, $L_{1}, L_{2}$, and $L_{m}$ are the stator leakage, rotor leakage, and magnetizing inductances in the motor's T-equivalent circuit, respectively.

$$
\begin{aligned}
& \underline{L}=\left[\begin{array}{ccccc}
\left(L_{A A}-L_{A C}-L_{B A}+L_{B C}\right) & \left(L_{A B}-L_{A C}-L_{B B}+L_{B C}\right) & \left(L_{A a}-L_{B a}\right) & \left(L_{A b}-L_{B b}\right) & \left(L_{A c}-L_{B c}\right) \\
\left(L_{B A}-L_{B C}-L_{C A}+L_{C C}\right) & \left(L_{B B}-L_{B C}-L_{C B}+L_{C C}\right) & \left(L_{B a}-L_{C a}\right) & \left(L_{B b}-L_{C b}\right) & \left(L_{B c}-L_{C c}\right) \\
\left(L_{a A}-L_{a c}\right) & \left(L_{a B}-L_{a c}\right) & L_{a a} & L_{a b} & L_{a c} \\
\left(L_{b A}-L_{b C}\right) & \left(L_{b B}-L_{b C}\right) & L_{b a} & L_{b b} & L_{b c} \\
\left(L_{c A}-L_{c C}\right) & \left(L_{c B}-L_{c C}\right) & L_{c a} & L_{c b} & L_{c c}
\end{array}\right] \\
& \underline{R}=\left[\begin{array}{ccccc}
\left(r_{A}+r_{\text {thy } A}\right) & -\left(r_{B}+r_{\text {thy } B}\right) & 0 & 0 & 0 \\
\left(r_{C}+r_{\text {thy } C}\right) & \left(r_{B}+r_{\text {thy } B}+r_{C}+r_{\text {thy } C}\right) & 0 & 0 & 0 \\
0 & 0 & r_{r} & 0 & 0 \\
0 & 0 & 0 & r_{r} & 0 \\
0 & 0 & 0 & 0 & r_{r}
\end{array}\right]
\end{aligned}
$$

The inductance and resistance matrices are given in (14) and (15), shown at the top of the page. For further details, [15] should be consulted.

\section{References}

1. D. W. Novotny and F. Fath, "Analysis of induction machines controlled by series connected semiconductor switches", IEEE Trans. Power App. Syst., vol. PAS-87, no. 2, pp. 597-605, Feb. 1968. 
2. T. A. Lipo, "The analysis of induction motors with voltage control by symmetrically triggered thyristors", IEEE Trans. Power App. Syst., vol. PAS-9, no. 2, pp. 515-525, Mar./Apr. 1971.

3. P. C. Krause, O. Wasynczuk and S. D. Sudhoff, Analysis of Electric Machinery and Drive Systems, NJ, Piscataway:IEEE Press, 2002.

4. S. S. Murthy and G. J. Berg, "A new approach to dynamic modeling and transient analysis for SCR-controlled induction motors", IEEE Trans. Power App. Syst., vol. PAS-101, no. 9, pp. 31413150, Sep. 1982.

5. G. Nath and G. J. Berg, "Transient analysis of three-phase S.C.R. controlled induction motors", IEEE Trans. Ind. Appl., vol. IA-17, no. 2, pp. 133-142, Mar./Apr. 1981.

6. A. P. Van den Bossche and J. A. Melkebeek, "Induction machine SCR voltage reduction: Optimized control and dynamic modeling", Proc. IEE Conf. Power Electron and Variable Speed Drives, 1984.

7. D. Gritter, D. Wang and T. G. Habetler, "Soft starter inside delta motor modeling and its control", Proc. IEEE-IAS Annu. Meeting, vol. 2, pp. 1137-1141, 2000-Oct.-8-12.

8. G. Zenginobuz, I. Cadirci, M. Ermis and C. Barlak, "Soft starting of large induction motors at constant current with minimized starting torque pulsations", IEEE Trans. Ind. Appl., vol. 36, no. 5, pp. 1337-1347, Sep./Oct. 2000.

9. H. Shaogang, H. Huagao, L. Guoyong and C. Weidong, "Simulation of soft start-up process of induction motors using hybrid variable model", Proc. 5th Int. Conf. Elect. Mach. and Syst., pp. 459-462, 2001-Aug.-18-20.

10. T. M. Rowan and T. Lipo, "A quantitative analysis of induction motor performance improvement by SCR voltage control", IEEE Trans. Ind. Appl., vol. IA-19, no. 4, pp. 545-553, Jul./Aug. 1983.

11. W. Deleroi, J. B. Woudstra and A. A. Fahim, "Analysis and application of three-phase induction motor voltage controller with improved transient performance", IEEE Trans. Ind. Appl., vol. 25, no. 2, pp. 280-286, Mar./Apr. 1989.

12. A. Ginart, R. Esteller, A. Maduro, R. Pinero and R. Moncada, "High starting torque for AC SCR controller", IEEE Trans. Energy Convers., vol. 14, no. 3, pp. 553-559, Sep. 1999.

13. B. Mirafzal and N. A. O. Demerdash, "A nonlinear controller for current source inverter induction motor drive systems", Proc. Int. Elect. Mach. and Drives Conf., vol. 3, pp. 1491-1497, 2003-Jun.

14. P. C. Krause and C. H. Thomas, "Simulation of symmetrical induction machinery", IEEE Trans. Power App. Syst., vol. PAS-84, no. 11, pp. 1038-1053, Nov. 1965.

15. M. G. Solveson, Soft started induction motor modeling and heating issues for different starting profiles using a flux linkage ABC-frame of reference, May 2004.

16. J. F. Bangura, R. J. Povinelli, N. A. O. Demerdash and R. H. Brown, "Diagnostics of eccentricities and bar/end-ring connector breakages in polyphase induction motors through a combination of time-series data mining and time-stepping coupled FE-state-space techniques", IEEE Trans. Ind. Appl., vol. 39, no. 4, pp. 1005-1013, Jul./Aug. 2003. 